Please quote as: Peters, C.; Blohm, I. \& Leimeister, J. M. (2015): Anatomy of Successful Business Models for Complex Services: Insights from the Telemedicine Field. In: Journal of Management Information Systems (JMIS), Ausgabe/Nummer: 32, Vol. Applied Science/Engineering Research Anatomy of Successful Business Models for Complex Services: Insights from the Telemedicine Field, Erscheinungsjahr/Year: 2015. pp. 75-104. 


\title{
Anatomy of Successful Business Models for Complex Services: Insights from the Telemedicine Field
}

\author{
CHRISTOPH PETERS, IVO BLOHM, AND JAN MARCO LEIMEISTER
}

Christoph Peters (corresponding author: Christoph.Peters@unisg.ch) is a researcher at the Institute of Information Management, University of St. Gallen, Switzerland, and at the Institute of Information Systems, Kassel University, Germany. He graduated from University of Mannheim, Germany and holds a Ph.D. from Kassel University. He has been a visiting researcher at the Service Research Center (CTF) at Karlstad University, Sweden, and the Recanati Business School of Tel Aviv University, Israel. He coordinates several research projects and heads a research group which focuses on the engineering and management of services and service systems, their digitization and corresponding business models.

Ivo Bцонм is a lecturer at the Institute of Information Management, University of St. Gallen. He holds a Ph.D. from Technische Universität München, Germany. He has been a visiting researcher at Harvard University, University of Queensland, and University of Verona. He heads the Competence Center Crowdsourcing at the University of St. Gallen - a research group at the Institute of Information Management, bundling several publicly and industry-funded research projects on crowdfunding, crowdsourcing, open innovation, and the Internet economy.

JAN MARCo Leimeister is chair of Information Systems and director of the Institute of Information Management at the University of St. Gallen, Switzerland, and chair of Information Systems and director of the Research Centre for Information Systems Design at Kassel University, Germany. He heads research groups and competence centers on crowdsourcing, virtual communities, service design and service management, and collaboration and learning engineering, and manages several publicly and industry-funded research projects. His research areas include digital business and transformation, IT innovation management, service science, ubiquitous and mobile computing, collaboration engineering, and business engineering.

The authors thank all the experts who participated in the interview series, Theresa Kromat for her commitment in the early phases of the research, and the reviewers and editors who provided excellent comments and feedback during all revision phases.

(C) Christoph Peters, Ivo Blohm, and Jan Marco Leimeister

This is an Open Access article. Non commercial re use, distribution, and reproduction in any medium, provided the original work is properly attributed, cited, and is not altered, trans formed, or built upon in any way, is permitted. The moral rights of the named author(s) have been asserted. 
ABSTRACT: Telemedicine services may improve the quality of life of individuals while also reducing the costs of service provisioning. They represent an important but as yet understudied type of complex services that integrates many stakeholders acting in service value networks. These complex services typically comprise a combination of information technology (IT) services and highly person-oriented, non-IT services, and are characterized by long service delivery periods. In such an environment, it is particularly difficult to generate successful and sustainable business models, which are necessary for the widespread provision of telemedicine services. Following a design research approach, we develop and evaluate the CompBizMod framework, a morphological box allowing for: (1) the analysis, description, and classification of telemedicine business models, (2) the identification of white spots for future business opportunities, (3) and the identification of patterns for successful business models. We contribute to the literature by presenting a specific business model framework and identifying three business model patterns in the telemedicine industry. We exhibit how business models for complex services can be decomposed into their constituent elements and present an easy and replicable approach for identifying business model patterns in a given industry.

KEY WORDS AND PHRASES: analysis frameworks, business model, business model pattern, complex service, telemedicine.

\section{Motivation}

Service has become an important field for research in information systems [53], as information technology (IT) revolutionizes the way services are delivered. Many services hereby not only play a key role for societal advancements, but become necessary for a well-functioning society [35]. IT enables new forms of cooperation and communication in services [53] as well as automation, standardization, and new concepts for customer integration [22].

In the health sector, which is of utmost importance for all societies [9], this is the case as well, and expresses itself in the form of telemedicine services. These telemedicine services realize medical treatments over a distance using means of IT [68] and can play a substantial part for the prevention, diagnosis, and treatment of diseases [52]. Through three different roles that information systems play in such services, medical advancements can be reached: (1) Telemedicine services can enable medical service provision in contexts where it was not possible before [43]. (2) They can support physicians and other health-care providers in offering IT-supported medical services in a better, more efficient manner [45]. And (3) telemedicine services can empower patients to take control of their health status and medical treatment [4].

These telemedicine services are - as are all complex services — characterized by a combination of IT services and non-IT, highly person-oriented, and often knowledge-intensive services [42]. Their provision includes many stakeholders acting in service value networks. Long service delivery periods are also typical for complex services, that is, they span several weeks or months in which continuous interactions are required for the service to harness its value.

Due to this complexity, it is particularly difficult to analyze the business models of complex service providers without a clearly given structure. The CompBizMod 
(short for: Complex Services Business Model) framework we present here aims at providing insights into four substantial features of business models: (1) a thorough description of the service offering's value proposition, its value co-creation, value transfer, and value capture; (2) an analysis of the business model itself, especially its constituent parts and their parameters' characteristics, (3) the role of information systems in providing the service and its underlying business model, and (4) the identification of dominating business model patterns. By their nature, business models are developed for the realization of competitive advantages. Thus, the CompBizMod framework is not limited to a provider's own business model analysis, but also allows a provider to distinguish and to evaluate business model dimensions of competing providers.

Hence, we present the development and evaluation of the CompBizMod framework for such business models, while providing insights and elaborating results. This framework allows one to analyze, describe, and classify the inner workings of business models for telemedicine services and thus constitutes an important contribution to the field of telemedicine, while it also extends the broader field of service science by exhibiting how specific service science principles can be integrated into business model innovation [37]. Besides the novel framework, we present a replicable application process for the CompBizMod framework with which we are able to identify three business model patterns for telemedicine services that exhibit how the role of information systems (i.e., enablement, support, and empowerment) in providing the telemedicine service shapes the dominating business model patterns in the telemedicine industry. Beyond providing an industry-specific business model framework that instantiates the notions of competition and information systems into a business model framework, we also contribute to the business model literature by providing a simple and intuitive approach for identifying business model patterns within a given industry.

Related Work: Fundamentals of Complex Services, Telemedicine, and Business Models

For telemedicine services at the edge of digitization, business models have still not been studied in detail, even though business model research on services with an information system focus dates back more than a decade [2, 31, 39, 54, 57, 64, 66]. In this section, we outline related work for complex services, the field of telemedicine, and business models.

\section{Complex Services}

A service itself is "(a set of) activities being part of interactions between the components of service systems" [34, p.22]. Complex services integrate many stakeholders acting in service value networks. Also, it is typical for complex services to span several weeks or months in which continuous interactions are required for the 
service to harness its value, that is, they require long service delivery periods. Thereby, complex services consist of combinations of both IT and non-IT services, while the latter integrate highly knowledge-intensive, person-oriented [42], and interactive parts as well. Service science deals with precisely such complex services because it focuses on hybrid offerings and the design of service systems while integrating a service-dominant logic [13]. This service-dominant logic provides "just the right perspective ... on which to build a theory of service systems, their configurations, and their modes of interaction" [36, p.18]. This perspective introduced by Vargo and Lusch $[59,61]$ focuses on the co-creation of value [60] within to-be-coordinated service networks [19], and is characterized by interdisciplinary efforts to be made [6]. According to Maglio and Spohrer's [36] research manifesto for service science, "the ultimate goal is to apply scientific understanding to advance our ability to design, improve, and scale service systems for business and societal purposes (e.g., efficiency, effectiveness, and sustainability)" (p.20).

While complex services are provisioned in service systems, that is, work systems generating a service [3], comprising a plethora of stakeholders, activities, and so on, the providers are the focus of business model considerations. Here, business model research can be crucial [38] and for innovating a provider's business model, it is especially important to integrate service science principles [37]. In this context, Maglio and Spohrer [37] argue that four service science principles must be considered: (1) service system entities dynamically configure resources such as people, technologies, organizations, and information; (2) service system entities consider concerns from involved stakeholders and thereby determine value; (3) the access to resources is reconfigured by mutually agreed-to value propositions; and (4) there are informal processes that guide the interactions between service system entities [37].

\section{The Field of Telemedicine}

All societies need health-care services - making it a truly enormous market. Global expenditure on health care has reached $\$ 7.2$ trillion [18]. In the past decade, great advancements have been realized and telemedicine services have had enormous growth rates. For example, the European market is expected to reach $\$ 5$ billion by 2015 [21]; globally, it is predicted to increase from \$23 billion in 2015 [7] to an expected \$43.5 billion in 2019 [8]. Although in many different forms [23], telemedicine services are relevant for all continents. Telemedicine-dedicated device and software markets - estimated at \$843 million in 2012 - are anticipated to reach \$2.9 billion by 2019 , while mobile health markets related to telemedicine currently at $\$ 1.4$ billion are anticipated to reach $\$ 1.5$ trillion by 2019 due to the use of 7 billion smartphones plus half that many connected tablet devices [65].

Offered telemedicine services are of a heterogeneous nature, ranging from telemonitoring services (e.g., defibrillators that capture and transfer a patient's heartbeat data in order to enable physicians to remotely monitor the patient's heart functions and to automatically trigger alarm functions) to teleconsultation services enabling 
experts to guide other physicians in conducting medical procedures, for example, in telestroke units. The heterogeneity also applies to the telemedicine services context. Telemedicine services are used at various stages of the overall treatment process of patients - for example, before the discharge of patients from hospitals in order to assist in improving a patient's rehabilitation [55]. They might be applied at very remote locations involving different concepts and levels of existing knowledge [43], or in developing countries facing very low ratios of health professionals to population, thus allowing telemedicine services to mitigate the shortage of medical personnel [1]. Also, telemedicine services concern all age groups, which thus require specific handling and different practice styles [40], such as in service co-creation processes with the elderly [41].

Telemedicine services always comprise a combination of IT services and highly person-oriented services. IT services might involve the data transfer of a telemedicine service device to a monitoring facility. Due to industry standards or technical input and output requirements, these parts are highly standardized. Non-IT parts might be knowledge-intensive and person-oriented service parts-for example, an interaction between physician and patient that could be highly individual in view of the patient's individual state and situation. Such telemedicine services are beneficial in supporting a patient's quality of life [9] and, where implemented, can reduce the cost of delivering health care. Despite being considered medically and technically viable, few telemedicine service innovations have been put into practice [17, 20]. The full potential of telemedicine services has not yet been unleashed, since many telemedicine providers have failed to develop profitable and sustainable business models [17].

\section{Business Model Frameworks}

A business model presents a company's core business activities, and its economic success consequently depends on an appropriate business model. Business models can serve as instruments for managers that strategically plan new business activities and develop existing ones [32].

Two of the most comprehensive and well-known studies in the business model literature are those by Osterwalder et al. [47, 48] and Wirtz [66]. While the business model canvas of Osterwalder et al. $[47,48]$ comprises the nine building blocks of customer segments, value proposition, channels, customer relationship, revenue streams, key resources, key activities, key partnerships, and cost structure, the approach of Wirtz [66] constitutes the following parts: market model, serviceoffering model, goods and services model, procurement/ distribution model, organization/cooperation model, and capital model. These are only two examples of business model frameworks that have been, and are being, widely discussed. However, business models and business model frameworks have many different aims. With respect to our three goals presented above (description, analysis, and classification), we attempted to identify the overarching building blocks of business 
models as a starting point for our design process. In so doing, we identified the most relevant business model frameworks from both the business model and telemedicine literature and compiled the single components of the investigated business frameworks into a concept matrix (see Table 1) [63].

As one can see, the single components of the frameworks vary widely, but converge to four overarching dimensions to analyze, describe, and classify the constituent parts of business models in the context of telemedicine services: (1) the value proposition of a service offering, (2) the mode of value co-creation between consumer and provider of the service, (3) the method of value communication and transfer to the service consumer, and (4) how value is captured by the service provider.

However, the work of Maglio and Sporer [37] suggests that the investigated business model frameworks fall short in their capabilities to analyze, describe, and classify business models of telemedicine services. Generally, a value proposition has been defined as an overall view of a company's bundle of products and services that are of value to the customer $[47,48]$. However, the role of the "paying customer" cannot easily be defined in the scope of telemedicine services, which usually involves four different entities operating in a service network: patients, health-care providers such as physicians or hospitals, insurance companies, and IT providers. Whereas telemedicine usually aims at improving service quality while also reducing the costs of service provision for patients as "end consumers," the definition of value propositions can be an arduous endeavor, insofar as the customer of a telemedicine service for whom value is created cannot be easily defined [14]. Value co-creation is the participation of consumers along with producers in the creation of value [71]. This is particularly true for services whose value creation depends on the integration of the service consumer into the service provision. Extending this argument, the production and consumption of telemedicine services are inseparable such that the created value is highly heterogeneous, as it also depends on the efforts of the consumer [69]. Value communication and transfer specify how the value is transferred to service consumers - that is, interaction and communication channels of value co-creation $[47,48]$. In this regard, telemedicine services as complex services require trust in the service provided with a high (personal) risk for the consumer. Furthermore, interaction and communication are facilitated by means of information systems. Consequently, value communication and transfer for telemedicine service may be of high importance for successful business models of telemedicine services. Finally, value capture describes the way in which service providers draw profit in complex service ecosystems [70]. Again, telemedicine does show a couple of peculiarities, as such markets tend to be highly regulated and services are frequently paid for by insurance companies. Consequently, the price of such services cannot function as a mechanism for matching demand and offer, as end consumers frequently do not pay directly for the services and service providers may be constrained in setting prices due to the regulatory environment [14].

Moreover, our analysis revealed that the investigated frameworks of the business model and telemedicine literature are agnostic regarding the role of information systems for the business model's implementation - that is, they do not provide any 


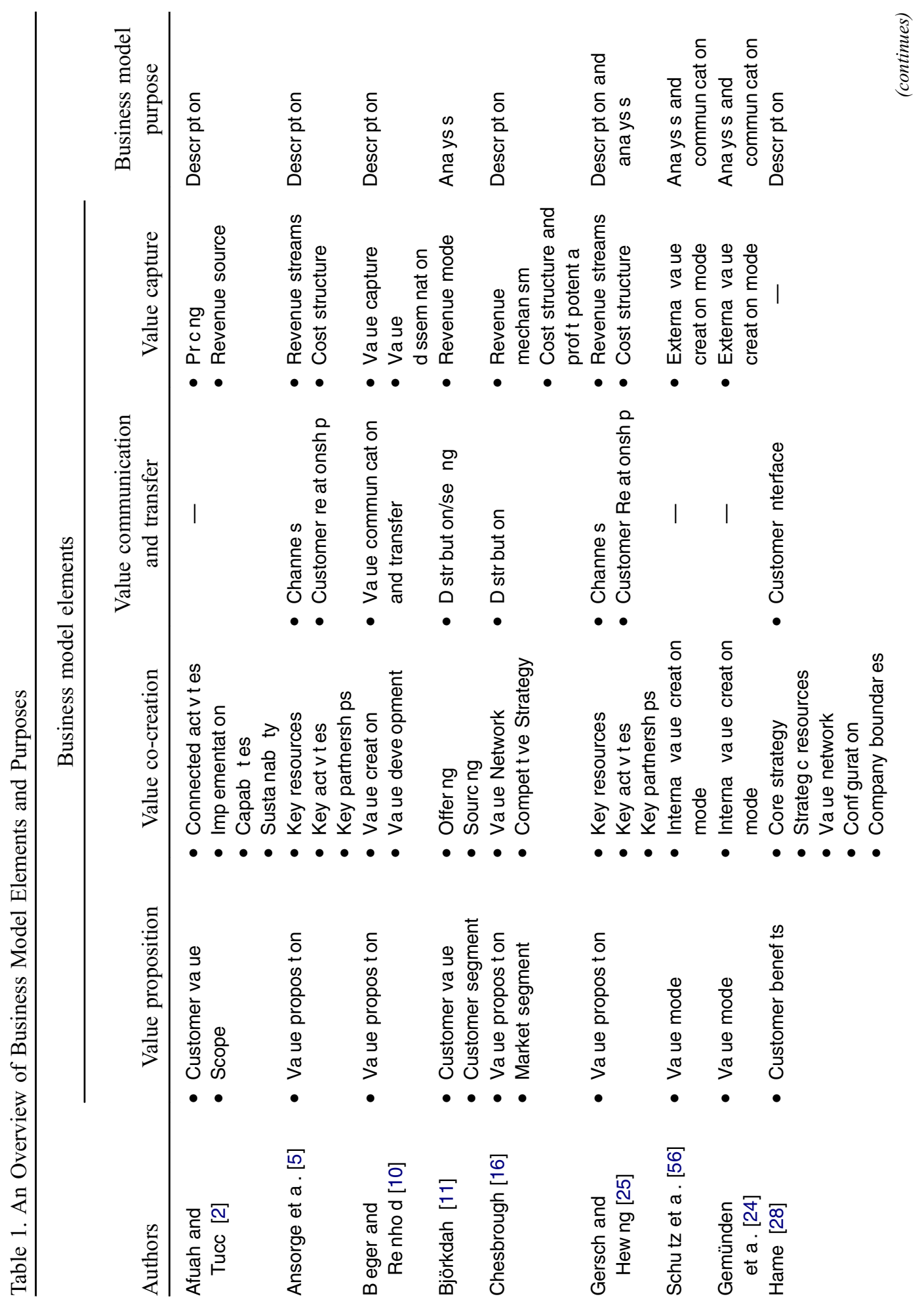




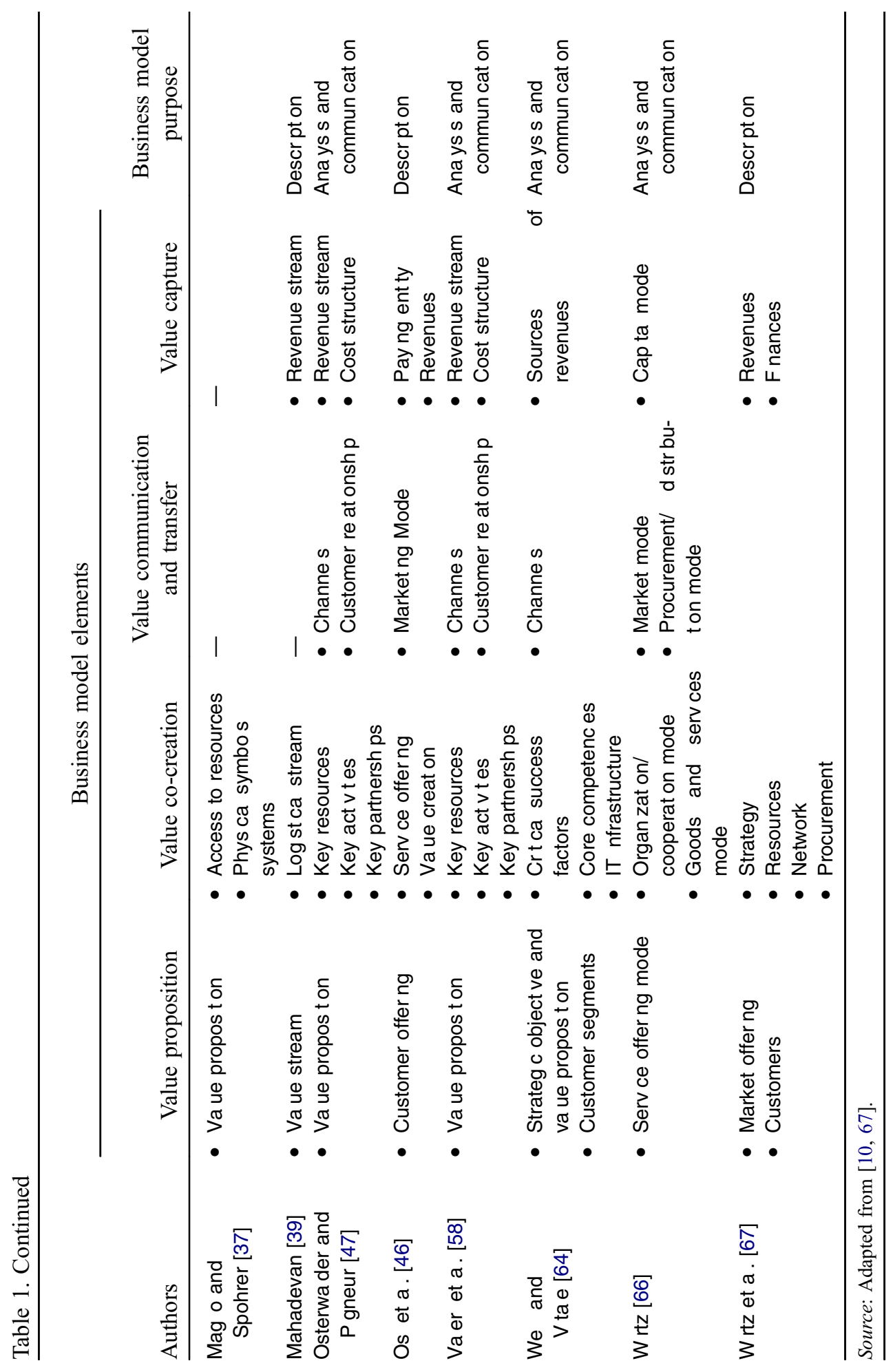


guidance on the facilitation of various parts of the business model by information systems in order to provide successful telemedicine services. Despite important contributions that describe Internet-based business models, in particular in the domain of e-commerce [2, 39, 66, 70], there is comparably little understanding about how information systems form business models [64]. This is particularly true when we turn to frameworks for analyzing, describing, and communicating business models [66]. However, as information systems are an essential part of telemedicine services, the proper integration of appropriately designed information systems is of high importance for a telemedicine service's acceptance, profitability, and sustainability. Given the increasing digitization of industries that did not extensively rely on digital business models, such as the health-care industry, there is a general need for insights on the constituent parts of business models, their facilitation and support by means of information systems, as well as their systematic design from scratch as an integral part of the business model [62].

In a similar fashion, existing business model frameworks usually focus on the inner workings of a business model and the interplay of the constituent parts. However, beyond facets such as strategy or gaining competitive advantages $[16,28,67]$, business model frameworks fall short in addressing the competitive arena in which a given business model is to be implemented. As a consequence, exploring competing business models or alternative options for one of a business model's constituent parts is complex and time-consuming, as each competitor has to be assessed in a step-by-step fashion.

\section{Research Approach}

We built and evaluated the CompBizMod framework following a design science research approach. We completed all three relevant cycles of design science research in an iterative fashion [29]: the relevance cycle, the rigor cycle, and the design cycle. The interconnections are visualized in Figure 1. The relevance cycle constitutes the connection between design activities and its environment of practice. More specifically, it enables the collection of requirements for solving the real-world problem

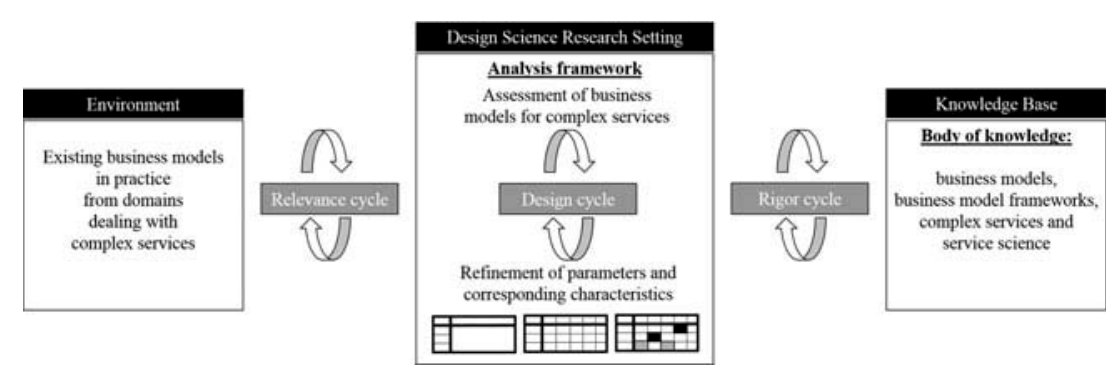

Figure 1. Design Science Research Setting

Source: Adapted in part from Hevner [29]. 
and the introduction of designed artifacts to the field. The rigor cycle is the connection between the design activities and the existing knowledge base. Thus, it integrates theories and existing knowledge and artifacts from the knowledge base to inform the research, while adding knowledge created within the design and research activities to the continuously growing knowledge base. Situated in the center, the design cycle represents close iterations of research activities for the construction and evaluation of the to-be-designed artifacts [29]. This design science research setting of our paper is visualized in Figure 1.

In three iterations, we developed the CompBizMod framework that allows for the analysis, description, and classification of telemedicine services. All iterations inherit a design cycle, a relevance cycle, and a rigor cycle. The resulting artifacts from the design cycle were informed by the environment (relevance cycle) and the knowledge base (rigor cycle) of the according iteration, and also transported findings back to the field (relevance cycle), and extended the existing knowledge base (rigor cycle) in each of the iterations.

The artifact of the first iteration can be best described as a first attempt in terms of a framework. It consisted of four main dimensions with their respective parameters. The second iteration resulted in the morphological box as the first real version of the CompBizMod framework and three business model patterns for the field of telemedicine. In our third and last iteration, a refined CompBizMod framework including refined business model patterns could be elicited. For the latter, the roles of information system vary, but are clearly definable. We describe the detailed process of how the relevance and rigor cycles informed the artifact(s) of the three iterations in the next section. Table 2 illustrates the three iterations of our design science research project. Each cycle is addressed in all three iterations.

\section{The CompBizMod Framework: Iterative Design and Evaluation}

The CompBizMod framework is supposed to have the form of a morphological box and therefore consists of dimensions with several parameters. Corresponding characteristics are given for all parameters. Only one characteristic per parameter can be chosen for each business model, which allows for a clear differentiation between the business models. The design of the framework took place in three iterations, which we describe in turn.

Within the first iteration, we started with a relevance cycle, which resulted in the identification of a lack of business models as an important class of unsolved problems in the domain of telemedicine services. We performed a rigor cycle by drawing on the existing body of knowledge regarding works on business models and corresponding frameworks, as well as service- and telemedicine-specific literature. We derived four dimensions that constitute the major building blocks of our framework: value proposition, value co-creation, value communication and transfer, and value capture. For each dimension, a set of parameters was identified by literature analyses, which make up the artifact of the first iteration (including value- and service-oriented aspects). 
Table 2. Overview of Performed Relevance, Design, and Rigor Cycles

\begin{tabular}{|c|c|c|c|}
\hline Iteration & Relevance cycle & Design cycle (result) & Rigor cycle \\
\hline 1 & $\begin{array}{l}\text { Elicitation of needs from } \\
\text { the field, integration of } \\
\text { domain-specific } \\
\text { parameters }\end{array}$ & $\begin{array}{l}\text { Four dimensions and } \\
\text { parameters with single } \\
\text { characteristics }\end{array}$ & $\begin{array}{l}\text { Existing business model } \\
\text { frameworks from } \\
\text { literature as input; } \\
\text { extending the } \\
\text { knowledge base by } \\
\text { business model } \\
\text { framework knowledge } \\
\text { for telemedicine } \\
\text { services }\end{array}$ \\
\hline 2 & $\begin{array}{l}\text { Sixteen existing } \\
\text { telemedicine business } \\
\text { models as input; } \\
\text { parameter-by- } \\
\text { parameter assessment } \\
\text { using initial framework; } \\
\text { identification of } \\
\text { business model } \\
\text { patterns }\end{array}$ & $\begin{array}{l}\text { Morphological box as } \\
\text { CompBizMod } \\
\text { framework plus first } \\
\text { versions of the three } \\
\text { business model } \\
\text { patterns }\end{array}$ & $\begin{array}{l}\text { Continued knowledge } \\
\text { extension regarding } \\
\text { business model } \\
\text { frameworks for } \\
\text { telemedicine services } \\
\text { and complex services } \\
\text { general; analytic } \\
\text { generalization of } \\
\text { identified business } \\
\text { model patterns against } \\
\text { business model } \\
\text { literature }\end{array}$ \\
\hline 3 & $\begin{array}{l}\text { Evaluation of } \\
\text { CompBizMod } \\
\text { framework and } \\
\text { business model } \\
\text { patterns with eleven } \\
\text { expert interviews }\end{array}$ & $\begin{array}{l}\text { Refined CompBizMod } \\
\text { framework and refined } \\
\text { business model } \\
\text { patterns; revelation of } \\
\text { the underlying roles of } \\
\text { information systems }\end{array}$ & $\begin{array}{l}\text { Continued knowledge } \\
\text { extension regarding } \\
\text { business model } \\
\text { frameworks for } \\
\text { telemedicine services } \\
\text { and complex services } \\
\text { general; specification } \\
\text { in regard to the varying } \\
\text { roles of information } \\
\text { systems }\end{array}$ \\
\hline
\end{tabular}

For the according derivation, the frameworks of Bieger and Reinhold [10] and Osterwalder et al. [47] were used, while also integrating Vargo and Lusch's perspective of service-dominant logic [59, 61]. All in all, the integration of these different aspects is intended to strengthen our analysis framework.

For the second iteration, a domain-specific consideration is necessary, as sixteen real-world business models of telemedicine service providers are used as input here. These business models were carefully selected in order to span a broad range of different business models representative for the telemedicine industry. The included business models were doc-to-doc and doc-to-patient settings that took place in airplanes, hospitals, and rural areas, involved stakeholder networks and single medical providers, and covered all medical treatment purposes, that is, prevention, diagnosis, treatment, and so on. We assessed the framework's dimensions and initial set of parameters from the first round by applying the business models from the 
telemedicine service providers and performed the relevance cycle of our second iteration. At this stage, each parameter's characteristic is described textually. Based on the sixteen filled-out frameworks with textually described parameters, we were able to enrich our insights from the relevance cycle by using a rigor cycle to come up with the structural pattern of our artifact: a morphological box. Thus, analyzing all of the dimensions parameter by parameter, their corresponding characteristics could be added, repositioned, or deleted. For each parameter, a set of predefined characteristics could be elicited this way. We then conducted another relevance cycle and assessed the existing sixteen business models from practice, thereby verifying that the chosen parameters and their corresponding characteristics are holistic for each of the dimensions. The framework has thus been refined and extended, given the insights from practice of this iteration. Also, the application of the newly created CompBizMod framework allowed for the identification of three patterns for business models in the field of telemedicine: enablement, support, and empowerment.

The framework of the second iteration was then evaluated with a series of eleven interviews with carefully selected experts. We contacted practitioners and researchers with a vast expertise in the domains of both telemedicine and business model development. In fact, all interviewees had personal experience in developing business models for telemedicine services. Table 3 provides an overview of the interviewees, their positions within their organizations, and their specific expertise. The interviews were conducted in a semistructured fashion in July and August 2015 and lasted up to 120 minutes. The interview guideline consisted of open questions regarding (1) the business model of the telemedicine service that the interviewees had developed, (2) the application of the CombBizMod framework to these business models, including an assessment of their dimensions, parameters, and according characteristics, (3) the process of identifying business model patterns using the CompBizMod framework, (4) the identified telemedicine business model patterns, and (5) the overall evaluation of the CompBizMod framework.

The evaluation followed a fourfold approach in which we focused on the value, validity, and applicability of our framework. During the evaluation, the experts were asked to apply the CompBizMod framework to a specific telemedicine service business model that they had designed on their own. In so doing, we discussed the general dimensions and characteristics of the framework based on each interviewee's specific domain of experience - an approach that is supposed to increase the validity of the responses and the feedback [33,44]. Also, the interviewees used the framework to classify their business model as one of the three business model patterns. Besides intensively discussing the exhaustiveness and the explanatory content of these business model patterns, this approach enabled us to verify whether the interviewees' business models were correctly identified as one of the three business model patterns in terms of concurrent validity. Finally, the interviewees were asked to assess the value as well as the applicability of the ComBizMod framework in relation to alternative approaches that they had used when designing the business models of their telemedicine service. Analyzing our data, each interview was transcribed. All data were discussed and analyzed by two independent researchers in an inductive fashion such that we could 
Table 3. Overview of Interview Partners

\begin{tabular}{|c|c|c|c|}
\hline No. & Function & Organization & $\begin{array}{l}\text { Developed telemedicine } \\
\text { service/business model }\end{array}$ \\
\hline 1 & CEO and founder & $\begin{array}{l}\text { Telemedicine } \\
\text { start-up }\end{array}$ & $\begin{array}{l}\text { Telemedicine service that enables } \\
\text { individuals to individually track and } \\
\text { improve their health status }\end{array}$ \\
\hline 2 & Project manager & $\begin{array}{l}\text { Technology } \\
\text { consultancy }\end{array}$ & $\begin{array}{l}\text { Telemedicine service that enables } \\
\text { patients with amyotrophic lateral } \\
\text { sclerosis to weekly document their } \\
\text { medical conditions by using a } \\
\text { standardized questionnaire }\end{array}$ \\
\hline 3 & Project manager & $\begin{array}{l}\text { Health-care } \\
\text { association }\end{array}$ & $\begin{array}{l}\text { Home-monitoring service that enables } \\
\text { patients with hypertension to check } \\
\text { their blood pressure by using } \\
\text { wearables }\end{array}$ \\
\hline 4 & $\begin{array}{l}\text { Head of research } \\
\text { and } \\
\text { development }\end{array}$ & $\begin{array}{l}\text { Regional telemedicine } \\
\text { research center }\end{array}$ & $\begin{array}{l}\text { Telemedicine software service that } \\
\text { supports communication between } \\
\text { rescue service and hospital }\end{array}$ \\
\hline 5 & CEO and founder & $\begin{array}{l}\text { Regional telemedicine } \\
\text { association }\end{array}$ & $\begin{array}{l}\text { Telemedicine service in the field of } \\
\text { mobile eye care in nursing homes }\end{array}$ \\
\hline 6 & Project manager & $\begin{array}{l}\text { Research transfer } \\
\text { institute }\end{array}$ & $\begin{array}{l}\text { Telemedicine service in the field of } \\
\text { ambient assisted living }\end{array}$ \\
\hline 7 & Research scientist & $\begin{array}{l}\text { Multinational software } \\
\text { corporation }\end{array}$ & $\begin{array}{l}\text { Various telemedicine service in the field } \\
\text { of IT-facilitated health-care service }\end{array}$ \\
\hline 8 & $\begin{array}{l}\text { Founder and } \\
\text { rechnology } \\
\text { consultant }\end{array}$ & $\begin{array}{l}\text { Technology } \\
\text { consultancy }\end{array}$ & $\begin{array}{l}\text { Telemonitoring platform for smart } \\
\text { medication that enables patients to } \\
\text { treat hemophilia at home under the } \\
\text { supervision of a physician }\end{array}$ \\
\hline 9 & Project manager & $\begin{array}{l}\text { Regional telemedicine } \\
\text { association }\end{array}$ & $\begin{array}{l}\text { Telemedicine service in the field of } \\
\text { mobile eye care in nursing homes }\end{array}$ \\
\hline 10 & Project manager & $\begin{array}{l}\text { Regional telemedicine } \\
\text { association }\end{array}$ & $\begin{array}{l}\text { Telemedicine service in the field of } \\
\text { business management software for } \\
\text { hospitals }\end{array}$ \\
\hline 11 & Research scientist & University & $\begin{array}{l}\text { Product-related telemedicine services in } \\
\text { the field of medical technology }\end{array}$ \\
\hline
\end{tabular}

elicit the central amendments to be performed in order to improve the relevance of the CompBizMod framework. In so doing, the expert-based evaluation enabled us to make important amendments to the CompBizMod framework - for example, the parameter "cost structure" was introduced or the parameter "application scope" was deleted from a former version of the framework. Within these three described iterations and based on the information gained from the relevance and the rigor cycles, we designed and tested the CompBizMod framework in the design cycles and thus provide a generalizable solution to the problem. By using the framework in real-world settings, we took the solution back to the practice environment and refined it by using a series of eleven expert interviews. We also extended the existing knowledge base by reporting our results back to the research community. 


\section{Discussion}

Our discussion follows a fourfold structure. First, we discuss how the CompBizMod framework allows us to analyze, describe, and classify the inner workings of business models for telemedicine services and give a detailed description of all its parameters and characteristics. Second, we discuss how this framework can be applied in order to identify business model patterns within a given industry, that is, how the application process of the CompBizMod framework works. Third, the three identified business model patterns are discussed using precise examples from the field of telemedicine. Fourth, the discussion focuses on the comparison of these three business model patterns.

Analyzing, Describing, and Classifying Business Models with the CompBizMod Framework

The CompBizMod framework addresses the particularities of telemedicine services through the integration of the dimensions, parameters, and corresponding characteristics as outlined in Figure 2.

In this context, it is important to know that only one characteristic should be chosen for each parameter; if more than one applies, the most suitable should be chosen. The according parameters of the CompBizMod framework are described below. This is a direct consequence from the feedback of the interviewees who asked for brief descriptions to further strengthen the framework's ease of application.

\section{Value Proposition}

Overall purpose: Which kind of medical treatment is the business model aiming at? Medical treatments can be preventive (i.e., used to assist in services mitigating the risk of diseases), diagnostic (i.e., used for the detection of diseases and symptoms),

\begin{tabular}{|c|c|c|c|c|}
\hline \multirow{5}{*}{$\begin{array}{l}\text { Dimension } \\
\text { Value Proposition }\end{array}$} & \multirow{2}{*}{\begin{tabular}{|l} 
Parameter \\
Overall purpose \\
\end{tabular}} & \multicolumn{3}{|l|}{ Characteristic } \\
\hline & & \begin{tabular}{|l|l|} 
Prevention & Diagn \\
\end{tabular} & Therapy, curat & Therapy, palliative \\
\hline & End consumer & Professional provider, physician (B2B) & \multicolumn{2}{|c|}{\begin{tabular}{|l} 
Patient, relatives (B2C) \\
\end{tabular}} \\
\hline & Partner network & $\begin{array}{l}\text { A fixed set of other partners } \\
\text { is involved }\end{array}$ & $\begin{array}{l}\text { A flexible, competing set of } \\
\text { parthers is involved }\end{array}$ & $\begin{array}{l}\text { No partners are involved, or } \\
\text { if at all indirectly }\end{array}$ \\
\hline & $\begin{array}{l}\text { Realization of benefits } \\
\text { for the patient }\end{array}$ & By application & \multicolumn{2}{|c|}{ (if at all) indirectly } \\
\hline \multirow[t]{4}{*}{ Value Co-Creation } & Portfolio role & $\begin{array}{l}\text { One of several offerings in } \\
\text { the same area }\end{array}$ & Complement offering & $\begin{array}{l}\text { Singular, stand-alone } \\
\text { offering }\end{array}$ \\
\hline & Contact with patient & $\begin{array}{l}\text { Direct } \\
\text { Not nocessary }\end{array}$ & Indirect & No \\
\hline & $\begin{array}{l}\text { Domain-specific } \\
\text { know-how }\end{array}$ & Not necessary & $\begin{array}{l}\text { Necessary, provided by own } \\
\text { employees / in-house }\end{array}$ & $\begin{array}{l}\text { Necessary, requires } \\
\text { cooperation with (external) } \\
\text { domain experts }\end{array}$ \\
\hline & $\begin{array}{l}\text { Required } \\
\text { responsi veness }\end{array}$ & Immediate personal reaction & $\begin{array}{l}\text { Automated immotiate info } \\
\text { forwarding, non-immediate } \\
\text { personal reaction }\end{array}$ & Non-critical \\
\hline $\begin{array}{l}\text { Value Communication } \\
\text { \& Transfer }\end{array}$ & $\begin{array}{l}\text { Required means of } \\
\text { communication* }\end{array}$ & $\mathrm{No}^{*}$ & Platform (server, database)* & $\begin{array}{l}\text { Measuring devices / } \\
\text { wearables \& platform* }\end{array}$ \\
\hline \multirow[t]{3}{*}{ Value Capture } & \multirow{2}{*}{$\begin{array}{l}\text { Type of revenue } \\
\text { Paying entity }\end{array}$} & Transaction-based & \begin{tabular}{|l|} 
Transaction-independent \\
\end{tabular} & Mixed \\
\hline & & Health insurance & \begin{tabular}{|l|l} 
& Other stakehol \\
\end{tabular} & \begin{tabular}{l|l} 
Ider & Mixed \\
\end{tabular} \\
\hline & Cost drivers & Personnel costs & Equipment & \\
\hline Color scheme legend $\mathrm{f}$ & each parameter: & & Comments: & \\
\hline Only this chara & eristic $\square$ Also this & $\begin{array}{l}\text { Not this } \\
\text { character }\end{array}$ & $\begin{array}{l}\text { *Internet, teleph } \\
\text { mobile data are }\end{array}$ & $\begin{array}{l}\text { lone, mobile phone incl. } \\
\text { considered as given }\end{array}$ \\
\hline
\end{tabular}

Figure 2. The CompBizMod Framework 
therapeutic or curative (i.e., aiming at healing a disease), or palliative (i.e., providing therapy that cannot have a healing effect, but aims at improving the life situation).

Service consumer: Who is the main beneficiary of the business model's value proposition? The service consumer can be a patient, a patient's relative, or a stakeholder playing a professional role in the health-care sector.

Partner network: Are there other business models partners who play an active part in the service provision process (besides the provider assessing the framework and the patient, e.g., equipment manufacturers)? Network partners may be integrated in a fixed or ad hoc fashion.

Realization of benefits for the patient: Does the patient benefit from the business model when it is applied as in doc-to-patient settings or in an indirect manner as in doc-to-doc settings where the patient plays no role in the business model's success?

\section{Value Co-Creation}

Portfolio role: Which role does the business model play in the provider's overall portfolio? The telemedicine service could be one of several offerings the provider offers in the same area, it could be part of a complementary offering (i.e., it is always in need of other accompanying services), or it could be a singular business model that can be realized "stand-alone."

Contact with patient: Which co-creating role does the patient play? Value cocreation may include a direct, an indirect, or no patient contact during service provision.

Domain specific know how: Does the successful application of the business model require domain-specific know-how (e.g., by a physician)? Domain-specific knowledge may or may not be required for a business model. In case it is required, it could be located in-house by own employees or provided by means of cooperation with other external stakeholders.

Required responsiveness: How critical is the business model in regard to the patient's health? Required responses may include an immediate personal reaction (e.g., when realizing medical support in emergencies occurring in aircrafts), an automated immediate forwarding of information (e.g., in telemonitoring settings where a later personal follow-up is sufficient), or no reaction at all in uncritical settings (e.g., for services that track nutrition for obese patients).

\section{Value Communication and Transfer}

Required means of communication: How does the service provider communicate with the service consumer? In this parameter, Internet, telephone, mobile phone including mobile data are always considered as given. If one of these means of communication is used, this parameter should still be assessed with "No." Next to these means of communication, is a platform (server, database) needed or a platform and measuring devices or wearables? 


\section{Value Capture}

Type of revenue: What type of revenues can be realized? A business model's revenues can be created on a transaction basis (e.g., payments for every treatment), transactionindependent (e.g., a "flat rate"), or consisting of a mixed-mode revenue stream.

Paying entity: Who covers the costs? Characteristics include health insurance companies (i.e., the primary health market), the patient (i.e., the secondary health market), other stakeholders (e.g., the employer, or costs split between several parties).

Cost drivers: What is the main cost driver for the business model? For this parameter, characteristics include personnel costs or cost for equipment (e.g., platform hosting, devices).

When referring back to the characteristics of telemedicine services, it becomes obvious that combinations of IT and non-IT services are represented in the parameters of the CompBizMod framework. This is also the case for the heterogeneity of stakeholders - for example, by the parameters that reflect partners in the service network.

The framework has a focus on the service provider; even telemedicine services always require a service system perspective. In a well-working service system, there is always at least one entity who is and needs to be responsible for the integration of resources and the coordination of co-creation mechanisms. In typical digital transformations in complex services domains, the provider could take over this important role. That is why we asked our experts to take this role in the interviews. They deemed the framework's structure as appropriate and the dimensions, parameters, and characteristics as exhaustive and valid for analyzing, describing, and classifying telemedicine service business models. Beyond the domain specificity of the framework, the structure as a morphological box was deemed as its biggest advantage in comparison to already existing approaches because this allows for a quick and preventive assessment of business models. As one expert mentioned: "I would greatly appreciate the development of such an excellent matrix ... that allows to evaluate a project in advance, respectively preventively in medical terms. That would be great!" Another expert praised the framework's applicability in terms of distinguishing and positioning of business models by stating: "This framework is especially useful in terms of a relatively quick exclusion of peculiarities [of the business model]. Some categories seem crystal-clear. But exactly these crystal-clear definitions allow for a self-positioning in terms of defining what does or does not constitute the own business model. This always helps when sharpening [the business model], especially in such a heterogeneous field."

\section{Identifying Business Model Patterns with the CompBizMod Framework}

The CompBizMod framework can also be applied to identify business model patterns, reflecting our second contribution. This application process comprises three main phases. 
In the first phase, the framework CompBizMod is taken as a starting point and checked for necessary adjustments to the parameters and their corresponding characteristics. If the framework was applied to other domains of complex services beyond telemedicine, some domain-specific changes may be required due to the adapted regulatory environments of telemedicine. In a second phase, a representative set of real-world business models from the domain to be studied is chosen and assessed using the CompBizMod framework. The assessment is performed for all dimensions and parameters. In the last phase, patterns for business models are elicited. The collection of all business model patterns for the studied domain represents the result of the successfully conducted CompBizMod framework. Beyond telemedicine, this application process should be capable of dealing with all fields of complex services. The described phases are visualized in Figure 3.

In the interview series with experts, we also evaluated the application process. Generally, the interviewees evaluated the framework as easy to apply. Almost all interviewees mentioned that applying the framework to their business models had inspired them to rethink and evaluate their business model in terms of structure, logic, and value. Thus, one expert stated: "I definitely give more thought to the functioning behind the business model. Concerning the logic, to what extent I should communicate with the patient, how to interact and possibly even when to communicate what exactly, and when the value creation for the customer sets in - that is what I learned from the framework." It was deemed as being particularly useful in harmonizing the perspectives of the different entities that are involved in telemedicine business models. In this vein, the main need mentioned was a brief description of all parameters that guides one through the framework in case there is no guiding interviewer, which we developed in the final iteration.
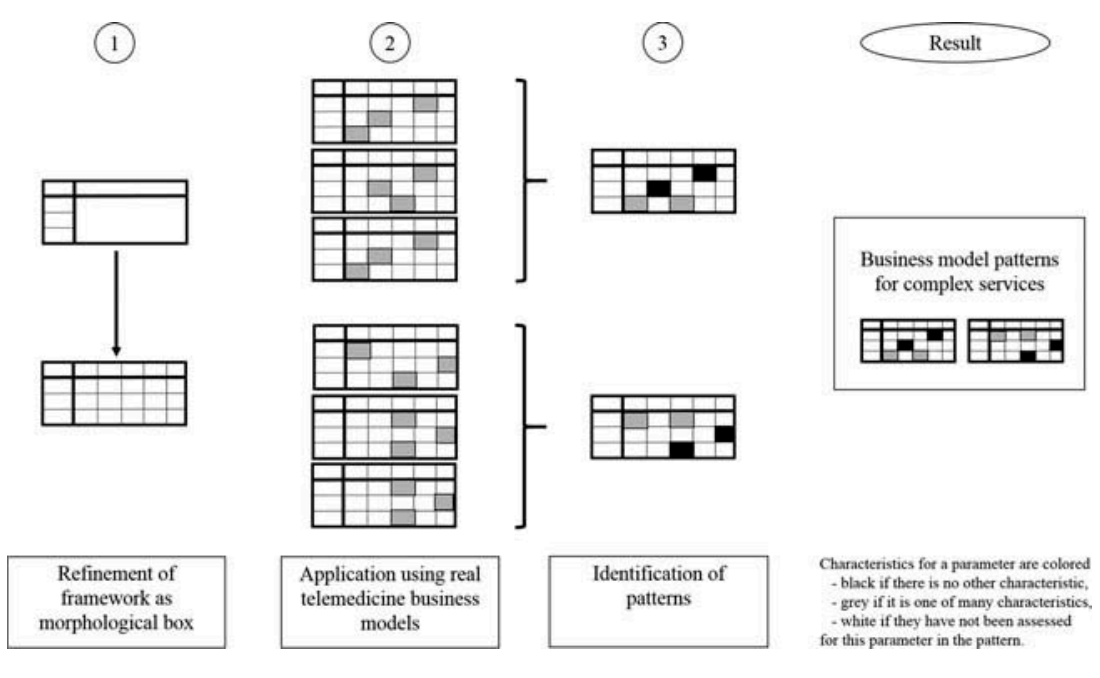

Figure 3. Application Process for the CompBizMod Framework 


\section{Three Identified Patterns}

In order to demonstrate the ability of our framework to classify business models and to identify business model patterns, we assessed sixteen business models from the field of telemedicine, which were clustered in three patterns. In greater detail, the three patterns that emerged represent frequently appearing configurations of the framework's parameter characteristics. In the interview series with experts, we also evaluated the patterns. The interviewees especially liked the clear structure of the patterns and the fact that they could easily match their own business models to the respective pattern. Also, many mentioned the capabilities of such patterns to structure the telemedicine market, underlined by expert comments such as "I am sure that the patterns will be greatly effective"; or "I like the patterns. They may be very helpful in terms of structuring all these telemedical activities."

\section{Pattern 1: "Enablement"}

"Enablement" business models take place in a business-to-business environment and have a partner network in which a flexible, competing set of partners is involved. The patient benefits from this kind of business model in an indirect manner. Providers of enablement business models provide other offerings in the same area and have no direct contact with the patient. These business models require some kind of platform infrastructure in the form of servers and databases. In order to co-create the business model's value, domain-specific know-how by external experts is necessary. During the delivery stage, no immediate responses are required to guarantee the business model's intention. A real-world example for an enablement business model from the field of telemedicine is a telemedical stroke network. A stroke, also known as cerebrovascular accident or brain attack, occurs when poor blood flow to the brain results in cell death. If detected within three to four and half hours, it may be treatable with a medication that can break down the clot. It is important to reduce the so-called door-to-needle time, that is, the period between the stroke and the administration of the medication treatment. This ideally takes place in a stroke center; however, such centers are most often only part of big hospitals in urban areas. With the business model of the telemedical stroke network, regional hospitals are connected with stroke centers in urban areas. Then, doc-to-doc telemedicine services are established that enable a direct connection between the expert in the specialized stroke center and physicians of regional hospitals . In a teleconsulting setting, the expert, using a video conferencing system, can take a look at the patient, talk to the patient directly, and examine the patient with the help of the local physician. Within minutes, the expert can now decide whether or not thrombolysis therapy is indicated. Information systems play an enabling role in these business models. Without the telemedical treatment-made possible by the information systems behind it - the service could not be offered at the rural hospitals. It is the enabled communication, data, and information exchange between the rural hospitals and the stroke centers that decreases the door-to-needle time. Thereby, the rural hospitals connected to the network improve the chance for a 
patient with a stroke to leave the hospital without severe disability, and patients in rural areas can now receive a highly specialized stroke treatment that used to be a privilege of patients living in larger cities with stroke centers.

\section{Pattern 2: "Support"}

"Support" business models take place in a business-to-business environment as well. Patients benefit directly from such business models and the service provision involves a fixed set of partners. Providers have indirect contact with the patient. In order to cocreate the business model's value, domain-specific know-how by external experts is necessary. The value proposition of support business models is to provide health-care institutions such as hospitals or physicians with offerings directed to patients. For the initial configuration of these patient-centered offerings as well as the correct service delivery and ongoing use of these offerings, medical know-how is needed. This is guaranteed by the medical personnel who recommend and deliver the service to the patients. The telemedicine service providers enable and facilitate the offerings from medical service providers to their patients, for example, by providing measuring devices, personal apps, and the related technical support for patients, while providing and maintaining the monitoring platforms for medical service providers.

Professional diabetes management is a typical real-world example for such a business model. Patients are provided with telemedicine devices, enabling the continuous measurement of their blood glucose values. Also, an app-based online diary for accompanying information is provided. The telemedicine service provider is responsible for all technical issues. Medical service providers such as physicians initially configure these offerings in a patient-centered manner and are provided with access to platforms which monitor the values of all their patients using these services. Not only can continuous health monitoring be realized, but medical incident management can also be supported by implementing event-triggered emergency notifications, that is, when a predefined threshold for vital data values is reached. These notifications can be forwarded to the patient's relatives, which is often done for very young patients who are not yet capable of managing themselves or very old patients who are no longer able to do so.

In this case, the role of information systems is a supporting one. In contrast to traditional service provisioning to patients with diabetes, where controlled, reliable blood glucose measuring was only possible during patient visits at the physician's site, a more continuous measurement can be accomplished - that is, it supports the physician in providing a better, more efficient service. In this case, the daily patient measurements support the physician.

\section{Pattern 3: "Empowerment"}

"Empowerment" business models take place in a business-to-consumer environment. The patient benefits from such business models directly. Providers of empowerment business models have direct contact with the patient. In order to co-create the business 
model's value, domain-specific know-how is necessary but is gathered by internal experts. Revenues are generated in a transaction-independent manner, for example, subscription-based. In the case of empowerment business models, typically telemonitoring is realized with consumers freely choosing to monitor their vital data. Therefore, a device is needed that is either part of the provider's overall offering or purchased separately by the consumer. By applying such business models, the patients and their physicians may receive a more detailed picture of their health status. There are many business models of this pattern, which are characterized by the "quantified self" movement and are realized through wearable information systems. Still, the empowerment pattern can be described by a business model dealing with amyotrophic lateral sclerosis (ALS), which is a specific disorder that involves the death of neurons. The disease leads to gradually increasing weakening of muscles, which results in difficulty speaking, swallowing, and eventually breathing. The disease is very rare, but became well-known during the ice bucket challenge in 2014. There are only few ALS specialists, which means that ALS patients can only visit ALS specialists every six to nine months during treatment and no information exchange is possible between visits. However, such patients frequently have a life expectancy of five years or less. With the help of the ALS business model, the patients are empowered to help in documenting their ALS health status and disease history. This is done with a standardized questionnaire. Because the muscle weakening leads to very restricted capabilities in speaking or motor skills, taking notes is very hard or impossible for the patient. Here, a poster based on near-field communication helps the patient to fill out the standard questionnaire in a continuous manner by holding a device and only touching predefined icons. For example, to document nutrition, the patient touches icons showing the amount of food consumed, the time needed, and other related information.

That is why the role of information systems for this and similar business models is described as empowerment - the patients themselves are empowered to play an important role in their own health management. If the measurement devices and the respective information systems did not exist, patients would still be dependent on the physician's (or other medical personnel) frequent availability. In these empowerment business models, the patients not only play an important co-creating part of the service delivery the physician is responsible for. Given their mental fitness, patients also get the chance to become much more aware of their health status and its changes due to certain life situations or habits, for example, the consumption of certain foods or drinks, the consequences for vital data when doing sports, and so on.

\section{Comparison of the Three Identified Patterns}

Along with the detailed discussion of the three identified patterns for business models of telemedicine services above, we present a comparative analysis of them.

In enablement business models, the integration of different health-care providers, such as hospitals and physicians working in doctors' offices, is a key focus. Therefore, an appropriate model needs to consider its different partners in the 
network and their different interests. To sum up, an enablement business model has to consider the whole value network while having no direct contact with the end consumer. Information systems have an enabling character in this context, as these business models were impossible to implement and execute without them as the foundation for the medical treatment.

In order to provide telemedicine service based on a support business model, the telemedicine service provider has to cooperate with external service providers. These external service providers are the health-care providers (consisting of different entities) as well as the health insurance companies. On the one hand, such cooperation allows the telemedicine service provider to outsource different activities, such as reimbursement issues. On the other hand, the telemedicine service provider is highly dependent on the external service providers' performances in delivering telemedicine service. Moreover, the health insurance companies and their interests have to be added in the support business model's representation as well. As for the role of information systems, it can be stated that traditional medical health care was possible in these areas of support business models before, but the respective service providers are now being supported in offering their services in a better or more efficient manner.

By applying an end-consumer patient-centered empowerment business model, telemedicine service providers can interact with their patients directly; external service providers as intermediaries are not needed, but might be integrated to improve quality. Health insurance companies are often excluded, as patients pay directly. In these business models, patients are empowered to take control of their health by means of information systems. This can have significant effects on a patient's overall awareness of his/her health status. It also creates new ways in which health-aware people might interact with medical experts, when at least parts of their health condition are much clearer to them than was the case without this continuously gathered and monitored health information and development. The advantages and disadvantages of the three patterns are presented in Table 4.

Important aspects elicited while analyzing support and empowerment business models are the consequences of direct contact with the patients. Depending on patients' age and health status, other individuals can also be involved-for example, parents, who pay for their child's medical treatment. They decide on the consumption of their child's or another patient's telemedicine service. This is why they have to be considered as consumers as well.

It also becomes obvious why most of the empowerment business models are much more successful than enablement or support business models. In such empowerment models, capturing value for service providers is much easier because they have direct contact and often take place in the secondary health market, where the patients are paying and no reimbursements from health insurance companies are needed. This might not be very surprising because direct contact allows them to realize all benefits that accompany co-creation of telemedicine services and a service-dominant logic perspective. 
Table 4. Advantages and Disadvantages of the Identified Business Model Patterns

\begin{tabular}{|c|c|c|}
\hline Pattern & Advantages & Disadvantages \\
\hline "Enablement" & $\begin{array}{c}+ \text { Revenues follow because of } \\
\text { service and maintenance }\end{array}$ & $\begin{array}{l}\text { - In order to profit, customers } \\
\text { (health-care providers) must } \\
\text { develop their own ideas for } \\
\text { telemedicine service applications }\end{array}$ \\
\hline "Support" & $\begin{array}{l}+ \text { Medical know-how is not } \\
\text { necessary } \\
+ \text { Outsourcing specific functions of } \\
\text { value creation, for example, } \\
\text { acquisition of customers or } \\
\text { patients, and reimbursement } \\
\text { issues }\end{array}$ & $\begin{array}{l}\text { - Being highly dependent on } \\
\text { external service providers; a } \\
\text { service provider influences a } \\
\text { service's quality significantly }\end{array}$ \\
\hline "Empowerment" & $\begin{array}{l}\text { Keeping in touch with recipients } \\
\text { directly; there is no health-care } \\
\text { provider between the } \\
\text { telemedicine service provider } \\
\text { and the patient; service quality is } \\
\text { influenced by the telemedicine } \\
\text { service providers (suppliers) } \\
\text { themselves } \\
+ \text { The patients probably have to pay } \\
\text { out-of-pocket }\end{array}$ & $\begin{array}{l}\text { - Developing a clientele; } \\
\text { cooperation with health-care } \\
\text { providers is necessary in order to } \\
\text { get access to a client's data } \\
\text { (patient data) }\end{array}$ \\
\hline
\end{tabular}

\section{Theoretical Implications}

This paper has presented the CompBizMod framework for the analysis, description, and classification of business models of telemedicine services. The framework is a morphological box that was designed and further developed during the entire design process by means of not only a theoretical basis but also insights gained from practice. With the application to sixteen services in the field of telemedicine and a series of eleven interviews with carefully selected experts in developing telemedicine service business models, three distinct business model patterns were elicited. The developed framework and its application reflect a theory of design and action [27], thereby responding to the call for the design of novel artifacts facilitating the engineering and management of service systems [12]. When positioning our contributions within the design science research knowledge contribution framework [26], our morphological box-style framework CompBizMod can be regarded as a nascent design theory that makes three important contributions.

First, we contribute to the telemedicine literature by developing a framework for analyzing, describing, and classifying telemedicine business models [15]. In comparison to existing business model frameworks [47, 66], our framework allows us to grasp the complexity of the domain. Whereas existing frameworks help to describe the constituent parts in a generic fashion, the CompBizMod framework provides a more fine-grained understanding of how such generic 
building blocks can be instantiated within the highly complex telemedicine industry. In this regard, the CompBizMod framework provides an overview of how four major dimensions (value proposition, value co-creation, value communication and transfer, and value capture) shape telemedicine business models on the macro level, and also how these dimensions can be implemented through specific design elements on the micro level (i.e., the single parameters and characteristics in the morphological box). Furthermore, we were able to identify three archetypal business model patterns reflecting a basic business model taxonomy [57]. This endeavor responds to the call of Zott et al. [70] to develop more precise business model taxonomies for specific industries. The three identified business model patterns for telemedicine enable us to better explain industry dynamics and the performance of telemedicine service providers. In this regard, the three identified business models, specifically, the notion of IT facilitation in these business models help us to better explain how digitalization changes the provision of health care. For instance, our analysis shows that information systems in particular amend the logic of how value is created by evolving three different modes in which service providers co-create value with their stakeholders, namely, enablement, support, and empowerment.

Second, our research contributes to the field of service science, as telemedicine services are a paragon and an important class of complex services. Although complex services are becoming common sense in our daily lives, they remain an understudied research area [49]. In particular, business models for complex services have not been studied so far [50]. Our framework is a first attempt to unravel the constituent parts of business models for complex services. In this regard, our framework allows us to unravel how bundling IT-based as well as non-IT-based services creates customer value, thus enabling us to analyze and describe the specifics of value co-creation in service ecosystems. Here, the particularities of complex services - constituting combinations of IT and non-IT parts, being part of service value networks with various stakeholders co-creating the service, and requiring long service delivery periods - are represented in the dimensions, parameters, and corresponding characteristics of the CompBizMod framework. It also allows us to cope with the challenge that consumers (i.e., entities that use the services) and customers (i.e., entities that pay service providers) are frequently not the same, which results in highly intransparent modes of value capture. In this regard, we extend the work of Maglio and Spohrer [37], as our CompBizMod framework responds to their call to develop novel approaches for innovating the business models of service providers: "managers will need new and better tools to apply the principles of service science in a manner that co-elevates innovativeness of entities (their firms, customers, and suppliers) equitably, sustainably, and resiliently" [37, p. 669]. Furthermore, we explicitly integrate service science principles into our framework's four main dimensions.

Third, we make an important contribution to the business model literature. In this research field, several frameworks have been developed for analyzing, describing, and classifying business models - for example, the business model canvas by Osterwalder 
et al. [48]. Beyond providing an industry-specific framework for analyzing, describing, and classifying business models, our design science setting results in an intuitive and easy-to-apply approach for identifying business model patterns. Existing frameworks predominantly focus on the inner workings of value creation and capture for a single business model. As a consequence, many existing approaches, such as the business model canvas [48] or the partial business model framework by Wirtz [66], neglect the explicit notion of competition. In this regard, our three-step design approach that develops a unified framework for analyzing business models in the telemedicine industry exhibits how generic business model frameworks can be enriched with the existing body of knowledge and specific industry expertise. Thus, our framework allows both the identification of archetypal business model patterns and the efficient exploration of competing business models. Although we started with a specific and newly designed business model framework for telemedicine services, we see no reason why our procedure should not be applicable to other business model frameworks. In a similar vein, our research contributes to this stream of literature by unraveling how information systems affect the constituent parts of business models. Whereas existing business model frameworks are agnostic regarding the role of information systems for implementing and executing these business models, our framework exhibits precisely which constituent parts of telemedicine service business models are facilitated by means of information systems and specifically what these changes look like. In greater detail, we demonstrate how the different uses of information systems in co-creating as well as communicating and transferring value shape the dominating business models in telemedicine industry. This is particularly important as more and more industries are affected by a digitization of business models.

Following Gregor and Hevner [26], our nascent design theory reflects an "improvement" for its capability to analyze, describe, and classify business models for telemedicine services and its ability to explain how information systems change the logic of value creation from a business model perspective. By contrast, the CompBizMod framework can be regarded as an "invention," when we refer its ability to elicit patterns for business models of telemedicine services, and to provide guidance for strategic and competitive decisions as well as for the application process of the CompBizMod framework.

\section{Practical Implications}

In addition to the identification of the three business model patterns, the CompBizMod framework guides providers of telemedicine services to challenge and further develop their own business models. First, it must be noted in particular that the instantiation of the four generic dimensions in single parameters and characteristics that can be regarded as design elements on the micro level helps practitioners to make an efficient quick assessment of their own business model. This is particularly useful in a highly complex environment such as the telemedicine industry. In this regard, the framework can help service providers to rethink their own business models because it presents a rather 
exhaustive set of alternatives with which they can compare their current practice. In contrast to alternative business model frameworks that do not provide the same level of support, service providers only need to check the applicability of design alternatives rather than being guided in the creation of new ones. However, the framework is also of value to providers of traditional health-care service because it helps them to understand how the digitization and the augmented role of information systems can affect the entire industry.

Extending this line of reasoning, our work provides a second practical contribution. Providers of telemedicine services, and more generally health-care providers, are also supported in the differentiation of their own business models in comparison to their competitors. Using the CompBizMod framework, service providers can efficiently assess their competitors' business models and come up with ideas about how to design and create their own features leading to competitive advantages, consequently fostering the informed design of features and leading to further competitive advantages. If service providers want to extend or adapt their portfolio, they can identify "white spots" by using thus far unused patterns of the attributes of the framework's dimensions to develop first ideas. Such white spots can be defined as superior knowledge that can be used by providers to address niches in their corresponding markets. Furthermore, the framework is intended to facilitate the provider's strategic positioning within the market, allowing for well-informed adaptations of existing business models in the future.

A third practical contribution is reflected in the three business model patterns that basically represent a business model taxonomy for telemedicine services. The taxonomy is theoretically grounded and empirically verified and provides a finegrained perspective on telemedicine business models while abstracting from single elements of specific business models. This taxonomy provides a comprehensive overview of the telemedicine industry. It will help service providers of telemedicine services to characterize potential competitors. However, the taxonomy also has important practical relevance for providers of traditional health-care services, as it may help them to understand the competitive arena arising due to a novel class of competitors and/or business partners. Thus, the ComBizMod framework serves as a starting point for understanding how the digital transformation affects telemedicine and health-care providers by helping to develop a better comprehension and systemization of differentiating characteristics within their business models.

\section{Limitations and Future Research}

It lies in the nature of our investigation that one limitation is the timeliness of our research, that is, the fact that we could include in our assessment only business models that were known to us up to time of submission of this paper. Still, the field is highly active and new models are created or adapted day by day. We tried to cope 
with this challenge by relying on a continuously updated source of offerings in the studied fields.

Also, only German business models have been assessed here and these might inherit attributes reflecting the specifics of the German health-care market, which is a highly regulated environment. Still, we consider our developed framework a good means for coping with regulated environments, as its dimensions and parameters-as in all environments - might require adaptation in the long-run, but this would certainly affect only a small part of the framework whereas the rest may remain the same. In this context, the adaption of our results and successful future business models is of great interest in order to react to the recently announced plans of big digitization players such as Google or Apple, which are aiming to increase their power within the IT-driven health-care environment, and accordingly, the telemedicine field.

In this paper, a clear focus on the provider is maintained, while always considering the development and delivery of telemedicine services within a service system. When extending research in this area, the provider's future role in service systems, for example, as the necessary service and value integrator within the network, is worth studying. These considerations increase in relevance as in complexity and involve acceptance issues for all stakeholders, which is always a huge challengefor example, the acceptance of telemedicine services by physicians [30]. Future research should prove the framework's applicability to additional domains and emphasize ensuring its reliability as well as elaborating its validity. In addition, adequate tool support for an even easier processing of our framework and the corresponding derivation of patterns for business models of complex services in other domains would be a worthy endeavor. Furthermore, as the framework CompBizMod visualizes the constituent elements of successful business models, concerns regarding the modularity of such business models as well as the systematic translation of such modular business models in modular service offerings should be investigated further [51].

\section{Conclusion}

In this paper, we presented the CompBizMod framework, which is based on the existing body of knowledge in the fields of telemedicine, service science, and business model frameworks. This framework was iteratively built and evaluated in three iterations by using a design science approach. Thereby, we contribute by:

- Presenting the CompBizMod framework itself, which includes dimensions that consider aspects from telemedicine and service science research, while still focusing on business model research. It can be used to describe, analyze, and classify business models for telemedicine services, but - as a real "first" (to the knowledge of the authors) - it can also be used to facilitate strategic decisions and succeed in a competitive environment.

- Designing a novel and industry-specific framework improving our understanding of how service science principles can be integrated in business 
model innovation by using a business model framework for the identification and illustration of the three dominating business model patterns in the telemedicine industry. This approach can be adapted to other fields or even other business model frameworks in order to facilitate the identification of business model patterns in an intuitive, easy-to-apply way.

- Extending the business model literature with a business model framework that explicitly entails the notion of competition and the distinct roles of information systems.

Given these main contributions, our nascent design theory reflects a theory of design and action [27], and thus extends the existing body of knowledge, thereby closing the rigor cycle [29] of our design science approach.

\section{REFERENCES}

1. Abera, A.A.; Mengesha, G.H.; and Musa, P.F. Assessment of Ethiopian health facilities readiness for implementation of telemedicine. Communications of the Association for Information Systems, 34, 1 (2014), 67.

2. Afuah, A., and Tucci, C. Internet Business Models and Strategies. Boston: McGraw Hill, 2003.

3. Alter, S. Metamodel for service design and service innovation: Integrating service activities, service systems, and value constellations. In Proceedings of the International Conference on Information Systems (ICIS 2011). Shanghai: AIS 2011.

4. Angst, C.M., and Agarwal, R. Patients take control: Individual empowerment with personal health records. Robert H. Smith School Research Paper no. RHS 06 013, 2004.

5. Ansorge, B.; Dünnebacke, D.; Dornberg, J.H.; and Amini, A. Möglichkeiten der Etablierung von telemedizinischen Lösungen im Gesundheitsmarkt am Beispiel des MeDiNa Systems [Possibilities for establishing telemedicine solutions in the health care market using the example of the MeDiNa system]. M. Gersch and J. Liesenfeld, Editors. Wiesbaden: Gabler Verlag, 2012, pp. 2758.

6. Bardhan, I.R.; Demirkan, H.; Kannan, P.K.; Kauffman, R.J.; and Sougstad, R. An interdisciplinary perspective on IT services management and service science. Journal of Management Information Systems, 26, 4 (2010), 1364.

7. BCC Research. Research Report Telemedicine: Opportunities for Medical and Electronic Providers. 2011. http://www.bccresearch.com/report/HLC014D.html.

8. BCC Research. Global Markets for Telemedicine Technologies. Wellesley, MA, 2014.

9. Berry, L.L., and Bendapudi, N. Health care: A fertile field for service research. Journal of Service Research, 10, 2 (2007), 111122.

10. Bieger, T., and S. Reinhold. Das wertbasierte Geschäftsmodell: Ein aktualisierter Strukturierungsansatz. In T. Bieger, D. zu Knyphausen Aufseß, and C. Krys (eds.), Innovative Geschäftsmodelle. Berlin: Springer, 2011, pp. 1370.

11. Björkdahl, J. Technology cross fertilization and the business model: The case of integrat ing ICTs in mechanical engineering products. Research Policy, 38, 9 (2009), 14681477.

12. Böhmann, T.; Leimeister, J.; and Möslein, K. Service systems engineering. Business and Information Systems Engineering, 56, 2 (2014), 8390.

13. Buhl, H.U.; Heinrich, B.; Henneberger, M.; and Krammer, A. Service science. Wirtschaftsinformatik, 50 (2008), 6065.

14. Busse, R., and Schreyögg, J. Management im Gesundheitswesen: eine Einführung in Gebiet und Buch [Management in Healthcare: An introduction to the healthcare domain and the book]. In J. Schreyögg (ed.), Management im Gesundheitswesen [Management in Healthcare]. Heidelberg: Springer, 2010. 
15. Chen, S.; Cheng, A; and Mehta, K. A review of telemedicine business models. TELEMEDICINE and e HEALTH, 19, 4 (2013), 287297.

16. Chesbrough, H. Business model innovation: Opportunities and barriers. Long Range Planning, 43, 23 (2010), 354363.

17. Cho, S.; Mathiassen, L.; and Gallivan, M. Crossing the chasm: From adoption to diffusion of a telehealth innovation. In G. León, A. M. Bernardos, J. R. Casar, K. Kautz, J. DeGross (eds.), Open IT Based Innovation: Moving Towards Cooperative IT Transfer and Knowledge Diffusion. Boston: Springer, 2008, pp. 361378.

18. Deloitte. 2015 Global Health Care Outlook: Common Goals, Competing Priorities. 2015.

19. Dong, S.; Johar, M.S.; and Kumar, R.L. A benchmarking model for management of knowledge intensive service delivery networks. Journal of Management Information Systems, 28, 3 (2011), 127160.

20. Essén, A. The emergence of technology based service systems: A case study of a telehealth project in Sweden. Journal of Service Management, 20, 1 (2009), 98121.

21. European Commission. Telemedicine. March 14, 2014. http://ec.europa.eu/digital agenda/en/telemedicine.

22. Fitzsimmons, J.A., and Fitzsimmons, M.J. Service Management: Operations, Strategy, and Information Technology. Boston: McGraw Hill/Irwin, 2005.

23. Gartner Industry Research, ed. Hype Cycle for Telemedicine. Stamford, CT: Gartner 2012.

24. Gemünden, H.G.; Hensel, K.; and Schultz, C. Erfolgsfaktoren telemedizinischer Dienstleistungen [Market entry strategies and network management as critical success factors for telemedicine services first empirical results]. Ergebnisse der TU Berlin im Auftrag des BMBF [Telemedicine Guide Germany 2003]. Darmstadt, Germany: Minerva, 2002.

25. Gersch, M., and Hewing, M, eds. AAL Geschäftsmodelle im Gesundheitswesen: Eine empirisch gestützte Typologie relevanter Grundtypen ökonomischer Aktivitäten zur Nutzung von Ambient Assisted Living in sich verändernden Wertschöpfungsketten [AAL Business models in health care: an empirically founded typology of relevant archetypes for economic activities Intended for the use of Ambient Assisted Living in changing value chains]. Wiesbaden: Gabler Verlag, 2012

26. Gregor, S., and Hevner, A.R. Positioning and presenting design science research for maximum impact. MIS Quarterly, 37, 2 (2013), 337356.

27. Gregor, S., and D. Jones. The anatomy of a design theory. Journal of the Association for Information Systems, 8, 5 (2007), 312335.

28. Hamel, G. Leading the Revolution. Boston: Harvard Business School Press, 2000.

29. Hevner, A.R. The three cycle view of design science research. Scandinavian Journal of Information Systems, 19, 2 (2007), 87.

30. Hu, P.J.; Chau, P.Y.K.; Liu Sheng, O.R.; and Kar Yan, T. Examining the technology acceptance model using physician acceptance of telemedicine technology. Journal of Management Information Systems, 16, 2 (1999), 91112.

31. Järvelä, P.; Loikkanen, J.; Tinnilä, M.; and Tuunainen, V.K. Business models for electronic commerce in the travel services. Information Technology and Tourism, 2, 3 (1999), 185196.

32. Kerkhoff, M.; Kromat, T.; and Peters, C. Geschäftsmodelle in der Telemedizin ein Ordnungsrahmen. Morphologie Telemedizinischer Dienstleistungen im Rahmen eines Wert und Serviceorientierten Geschäftsmodellansatzes. Working Paper Series. Kassel, 2014.

33. Koch, A.; Strobel, A.; Kici, G.; and Westhoff, K. Quality of the critical incident technique in practice: Interrater reliability and users' acceptance under real conditions. Psychology Science Quarterly, 51, (2009), 315.

34. Leimeister, J.M. Dienstleistungsengineering und management. Berlin: Springer Verlag, 2012.

35. Leimeister, J.M., and Peters, C. Gesellschaftlich notwendige Dienstleistungen soziale Innovationen denken lernen [Necessary Services for Society Learning to Think in Social Innovations], in WISO Diskurs Expertisen und Dokumentationen zur Wirtschafts und Sozialpolitik [WISO Discourse Expert Reports and Documentations on Economic and Social Policies], Arbeitspapier des Arbeitskreises Dienstleistungen der Friedrich Ebert 
Stiftung [Working Paper of the Working Group Services, Friedrich Ebert Foundation], Editor. 2012, Friedrich Ebert Foundation, Department of Economic and Social Policies: Bonn, Germany.

36. Maglio, P., and Spohrer, J. Fundamentals of service science. Journal of the Academy of Marketing Science, 36, 1 (2008), 1820.

37. Maglio, P.P., and Spohrer, J. A service science perspective on business model innova tion. Industrial Marketing Management, 42, 5 (2013), 665670.

38. Maglio, P.P.; Srinivasan, S.; Kreulen, J.T.; and Spohrer, J. Service systems, service scientists, SSME, and innovation. Communications of the ACM, 49, 7 (2006), 8185.

39. Mahadevan, B. Business models for Internet based e commerce: An anatomay. California Management Review, 42, 4 (2000), 5569.

40. McColl Kennedy, J.R.; Vargo, S.L.; Dagger, T.S.; Sweeney, J.C.; and v. Kasteren, Y. Health care customer value cocreation practice styles. Journal of Service Research, 15, 4 (2012), 370389.

41. McLoughlin, I.P.; Maniatopoulos, G.; Wilson, R.; and Martin, M. Inside a digital experiment: Co producing telecare services for older people. Scandinavian Journal of Information Systems, 24, 2 (2012), 1326.

42. Menschner, P.; Peters, C.; and Leimeister, J.M. Engineering knowledge intense, person oriented services: A state of the art analysis. In Proceedings of the Nineteenth European Conference on Information Systems (ECIS). Helsinki, 2011.

43. Miscione, G. Telemedicine in the Upper Amazon: Interplay with local health care practices. Management Information Systems Quarterly, 31, 2 (2007), 403.

44. Morgan, D.L. Focus Groups as Qualitative Research. Thousands Oaks, CA: Sage, 1996.

45. Neumann, C.L.; Menne, J.; Rieken, E.M.; Fischer, N.; Weber, M.H.; Haller, H.; and Schulz, E.G. Blood pressure telemonitoring is useful to achieve blood pressure control in inadequately treated patients with arterial hypertension. Journal of Human Hypertension, 25, 12 (2011), 732738 .

46. Osl, P.S., Ernst; Österle, Hubert; Fischer, Andy. Erfolgreiche Telemedizinlösungen und Kundenakzeptanz zukünftiger Weiterentwicklungen: Das Geschäftsmodell des Schweizer Zentrums für Telemedizin MEDGATE [Successful solutions for telemedicine and customer acceptance of future developments: The business model of the Swiss Center for Telemedicine MEDGATE]. In Tagungsband Ambient Assisted Living 2. Deutscher Kongress mit Ausstellung: Technologien Anwendungen Management. 2009. Berlin.

47. Osterwalder, A.; Pigneur, Y.; and Clark, T. Business Model Generation: A Handbook for Visionaries, Game Changers, and Challengers. Hoboken, NJ: Wiley, 2010.

48. Osterwalder, A.; Pigneur, Y.; and Tucci, C.L. Clarifying business models: Origins, present, and future of the concept. Communications of the Association for Information Systems, 16, 1 (2005), 1.

49. Peters, C. Together they are strong: The quest for service modularization parameters. In Proceedings of the Twenty Second European Conference on Information Systems (ECIS). Tel Aviv, 2014.

50. Peters, C.; Kromat, T.; and Leimeister, J.M. Complex services and according business models design and evaluation of an analysis framework in the field of telemedicine. In Forty Eighth Hawaii International Conference on System Sciences. Koloa, Kauai, 2015.

51. Peters, C., and Leimeister, J.M. TM ${ }^{3}$ : A modularization method for telemedical ser vices: design and evaluation. In Proceedings of the Twenty First European Conference on Information Systems (ECIS). Utrecht, 2013.

52. Peters, C., and Menschner, P. Towards a typology for telemedical services. In Ancilliary Proceedings of the Twentieth European Conference on Information Systems (ECIS). Barcelona, 2012.

53. Rai, A., and Sambamurthy, V. Editorial notes the growth of interest in services manage ment: Opportunities for information systems scholars. Information Systems Research, 17, 4 (2006), 327331. 
54. Rajala, R.; Rossi, M.; and Tuunainen, V.K. A framework for analyzing software business models. In Eleventh European Conference on Information Systems (ECIS). Naples, 2003.

55. San Nicolas Rocca, T.; Schooley, B.; and Joo, S. Design and development of a patient centered e health system to improve patient understanding at discharge. Communications of the Association for Information Systems, 34, 24 (2014), 453476.

56. Schultz, C.; Gemünden, H.G.; and Salomo, S. Akzeptanz der Telemedizin [Acceptance of Telemedicine]. S. Salomo, Editor. Darmstadt: Minerva, 2005.

57. Timmers, P. Business models for electronic markets. Electronic Markets, 8, 2 (1998), 38.

58. Valeri, L.; Giesen, D.; Jansen, P.; and Klokgieters, K. Business Models for eHealth. RAND Europe and Capgemini Consulting. 2010.

59. Vargo, S., and Lusch, R. Service dominant logic: Continuing the evolution. Journal of the Academy of Marketing Science, 36, 1 (2008), 110.

60. Vargo, S.; Maglio, P.; and Akaka, M. On value and value co creation: A service systems and service logic perspective. European Management Journal, 26, 3 (2008), 145152.

61. Vargo, S.L., and Lusch, R.F. Evolving to a new dominant logic for marketing. Journal of Marketing (2004), 117.

62. Veit, D.C.E.; Benlian, A.; Buxmann, P.; Hess, T.; Kundisch, D.; Leimeister, J. M.; Loos, P.; and Spann, M. Business models: An information systems research agenda. Business and Information Systems Engineering (BISE), 1 (2014), 4553.

63. Webster, J., and Watson, R.T. Analyzing the past to prepare for the future: writing a literature review. MIS Quarterly, 26, 2 (2002), xiii xxiii.

64. Weill, P., and Vitale, M. What IT infrastructure capabilities are needed to implement e business models. MIS Quarterly Executive, 1, 1 (2002), 1734.

65. Wintergreen Research, Inc. Telemedicine and M Health Convergence: Market Shares, Strategies, and Forecasts, Worldwide, 2013 to 2019. Lexington, MA, 2013.

66. Wirtz, B.W. Electronic Business. Wiesbaden: Gabler, 2000.

67. Wirtz, B.W.; Pistoia, A.; Ullrich, S.; and Göttel, V. Business models: origin, develop ment and future research perspectives. Long Range Planning (2015), doi:10.1016/j. 1rp.2015.04.001

68. World Health Organization. Telemedicine: Opportunities and developments in member states. In World Health Organization (ed.), Global Observatory for eHealth series. Geneva, Switzerland, 2010, pp. 188.

69. Zeithaml, V.A.; Parasuraman, A.; and Berry, L.L. Problems and strategies in services marketing. Journal of Marketing, 49, 2 (1985), 3346.

70. Zott, C.; Amit, R.; and Massa, L. The business model: Recent developments and future research. Journal of Management, 37, 4 (2011), 10191042.

71. Zwass, V. Co creation: Toward a taxonomy and an integrated research perspective. International Journal of Electronic Commerce, 15, 1 (2010), 1148. 